\title{
Small Band Gap Polymers Synthesized via a Modified Nitration of 4,7-Dibromo-2,1,3-benzothiadiazole
}

\author{
Ergang Wang, ${ }^{, \dagger}{ }^{\dagger}$ Lintao Hou, ${ }^{\ddagger}$ Zhongqiang Wang, ${ }^{\ddagger}$ Stefan Hellström, ${ }^{\dagger}$ \\ Wendimagegn Mammo, ${ }^{\dagger, \S}$ Fengling Zhang, ${ }^{\ddagger}$ Olle Inganäs, ${ }^{\ddagger}$ and \\ Mats R. Andersson ${ }^{*,+, \neq}$
}

Department of Chemical and Biological Engineering/Polymer Technology, Chalmers University of Technology, SE-412 96 Göteborg, Sweden, Biomolecular and Organic Electronics, IFM, Center of Organic Electronics, Linköping University, SE-581 83 Linköping, Sweden, and Department of Chemistry, Addis Ababa University, P.O. Box 1176, Addis Ababa, Ethiopia ergang@chalmers.se; mats.andersson@chalmers.se

Received July 2, 2010

\section{ABSTRACT}

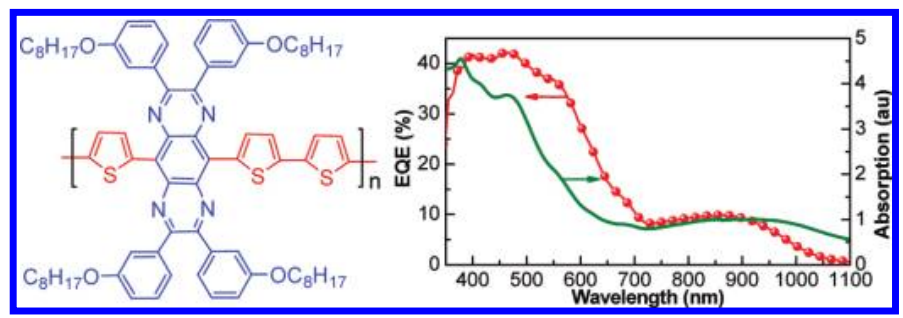

The nitration of 4,7-dibromo-2,1,3-benzothiadiazole was modified by using $\mathrm{CF}_{3} \mathrm{SO}_{3} \mathrm{H}$ and $\mathrm{HNO}_{3}$ as the nitrating agent, and the related yield was improved greatly. On the basis of this improvement, two new small band gap polymers, P1TPQ and P3TPQ, were developed. Bulk heterojunction solar cells based on P3TPQ and [6,6]-phenyl- $\mathrm{C}_{71}$-butyric acid methyl ester exhibit interesting results with a power conversion efficiency of $2.1 \%$ and photoresponse up to $1.1 \mu \mathrm{m}$.

Great progress has been achieved in the performance of polymer solar cells, ${ }^{1}$ especially after the introduction of the bulk heterojunctions (BHJ) concept ${ }^{2}$ with conjugated polymers as electron donors and fullerene analogues, such as [6,6]-phenyl- $\mathrm{C}_{61}$-butyric acid methyl ester ([60]PCBM) or $[6,6]$-phenyl- $\mathrm{C}_{71}$-butyric acid methyl ester ([70]PCBM), as electron acceptors. ${ }^{1}$ Yet, the commercialization of polymer solar cells is mainly limited by low-power conversion

Chalmers University of Technology.

Linköping University.

${ }^{\S}$ Addis Ababa University.

(1) (a) Cheng, Y. J.; Yang, S. H.; Hsu, C. S. Chem. Rev. 2009, 109, 5868. (b) Chen, H. Y.; Hou, J. H.; Zhang, S. Q.; Liang, Y. Y.; Yang, G. W.; Yang, Y.; Yu, L. P.; Wu, Y.; Li, G. Nat. Photonics 2009, 3, 649. (c) Park, S. H.; Roy, A.; Beaupre, S.; Cho, S.; Coates, N.; Moon, J. S.; Moses, D.; Leclerc, M.; Lee, K.; Heeger, A. J. Nat. Photonics 2009, 3, 297. (d) Bundgaard, E.; Krebs, F. C. Sol. Energy Mater. Sol. Cells 2007, 91, 954.

(2) Yu, G.; Gao, J.; Hummelen, J. C.; Wudl, F.; Heeger, A. J. Science 1995, $270,1789$. efficiencies (PCEs). One of the main reasons for the limited PCEs is the mismatch between the absorption spectra of polymers and the solar irradiation. ${ }^{1}$ High band gap polymers allow only a small fraction of the solar irradiation to be utilized. The development of small band gap polymers is critical to harvest more solar irradiation. An effective strategy is the combination of electron-rich and electron-deficient units to form alternating donor-acceptor structures, which are widely used to obtain small band gap polymers. ${ }^{1,3}$

Recently, 4,7-dibromo-5,6-dinitro-2,1,3-benzothiadiazole (2) has become an important intermediate compound for the synthesis of pyrazino[2,3-g]quinoxalines and thiadiazolo-

(3) (a) Wang, E. G.; Wang, L.; Lan, L. F.; Luo, C.; Zhuang, W. L.; Peng, J. B.; Cao, Y. Appl. Phvs. Lett. 2008, 92, 033307. (b) Blouin, N.; Michaud, A.; Gendron, D.; Wakim, S.; Blair, E.; Neagu-Plesu, R.; Belletete, M.; Durocher, G.; Tao, Y.; Leclerc, M. J. Am. Chem. Soc. 2008, 130, 732. (c) Huo, L.; Tan, Z. A.; Wang, X.; Zhou, Y.; Han, M.; Li, Y. J. Polvm. Sci. Polvm. Chem. 2008, 46, 4038. 
quinoxalines, which are highly electron-deficient units used for achieving small band gap polymers for solar cells, ${ }^{4}$ along with developing small molecules for near-infrared (NIR) applications. ${ }^{5}$ However, the widely used method for preparing 2 developed by Uno et al. ${ }^{6}$ was marred by very low yields $(20-30 \%)$. $^{4,5}$ We have now developed a more efficient method of preparing 2 by using nitronium trifluoromethanesulfonate (NTMS) as a nitrating agent. By taking advantage of the improved yield of $\mathbf{2}$, two new small band gap polymers were developed, and their photophysical, electrochemical, and photovoltaic properties were investigated.

The synthetic routes toward the two monomers are depicted in Scheme 1. As previously reported, ${ }^{4,6}$ the nitration

Scheme 1. Synthesis of the Two Monomers

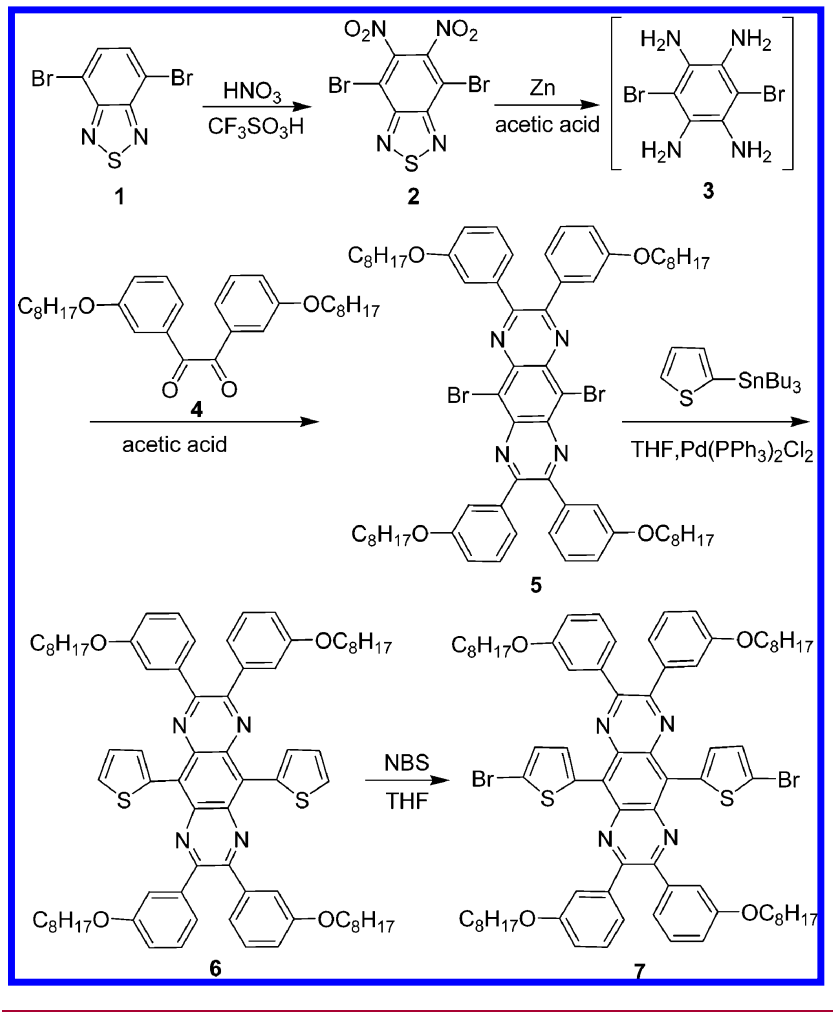

of 4,7-dibromo-2,1,3-benzothiadiazole (1) was carried out in a mixture of fuming $\mathrm{H}_{2} \mathrm{SO}_{4}$ and fuming $\mathrm{HNO}_{3}$. The yield of 2 was however very low. The main byproduct was the

(4) (a) Steckler, T. T.; Abboud, K. A.; Craps, M.; Rinzler, A. G.; Reynolds, J. R. Chem. Commun. 2007, 4904. (b) Zhang, F. L.; Bijleveld, J.; Perzon, E.; Tvingstedt, K.; Barrau, S.; Inganäs, O.; Andersson, M. R. J. Mater. Chem. 2008, 18, 5468. (c) Zoombelt, A. P.; Fonrodona, M.; Wienk, M. M.; Sieval, A. B.; Hummelen, J. C.; Janssen, R. A. J. Org. Lett. 2009, 11, 903. (d) Perzon, E.; Zhang, F. L.; Andersson, M.; Mammo, W.; Inganäs, O.; Andersson, M. R. Adv. Mater. 2007, 19, 3308. (e) Cai, T.; Zhou, Y.; Wang, E.; Hellström, S.; Zhang, F.; Xu, S.; Inganäs, O.; Andersson, M. R. Sol. Energy Mater. Sol. Cells 2010, 94, 1275. (f) Perzon, E.; Wang, X.; Admassie, S.; Inganäs, O.; Andersson, M. R. Polymer 2006, 47, 4261.

(5) (a) Qian, G.; Zhong, Z.; Luo, M.; Yu, D.; Zhang, Z.; Wang, Z. Y.; Ma, D. Adv. Mater. 2009, 21, 111. (b) Qian, G.; Li, X.; Wang, Z. Y. J. Mater. Chem. 2009, 19, 522. (c) Karikomi, M.; Kitamura, C.; Tanaka, S.; Yamashita, Y. J. Am. Chem. Soc. 1995, 117, 6791. 1909. mononitro compound, and the purification of the product mixture by chromatography was quite difficult. ${ }^{6}$ NTMS was shown to have excellent nitrating properties especially for the nitration of toluene. ${ }^{7}$ Thus, the nitration of 1 with NTMS as nitrating agent was carried out as follows: NTMS was obtained by mixing fuming $\mathrm{HNO}_{3}$ with fuming $\mathrm{CF}_{3} \mathrm{SO}_{3} \mathrm{H}$ carefully at $0{ }^{\circ} \mathrm{C}$, and then $\mathbf{1}$ was added into the mixture. First, the mixture was stirred at $0{ }^{\circ} \mathrm{C}$ for $5 \mathrm{~h}$, then thin layer chromatography (TLC) showed only a small portion of $\mathbf{1}$ turned to 2 . The reaction temperature was increased to room temperature and stirred overnight, but TLC still showed that a lot of 1 was left unreacted. Finally, the reaction temperature was increased to $50{ }^{\circ} \mathrm{C}$, and after $12 \mathrm{~h}$, TLC showed that $\mathbf{1}$ was completely converted. The pure $\mathbf{2}$ was obtained with a high yield of $85 \%$ after simple purification by recrystallization from ethanol, which is much simpler compared to the previously reported method. ${ }^{6}$ Compound $\mathbf{2}$ was reduced with zinc in glacial acetic acid and several drops of water ${ }^{4 \mathrm{~b}}$ to yield the tetraamine $\mathbf{3}$, which was condensed with diketone 4 immediately since the tetraamine is not so stable. Monomer 5 was obtained in moderate yield and was then combined with tributylstannyl thiophene to yield $\mathbf{6}$, followed by bromination with $N$-bromosuccinimide to yield monomer 7 in high yield. As shown in Scheme 2, the polymerization of

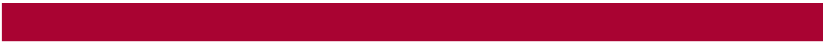

Scheme 2. Synthesis of the Two Polymers P1TPQ and P3TPQ

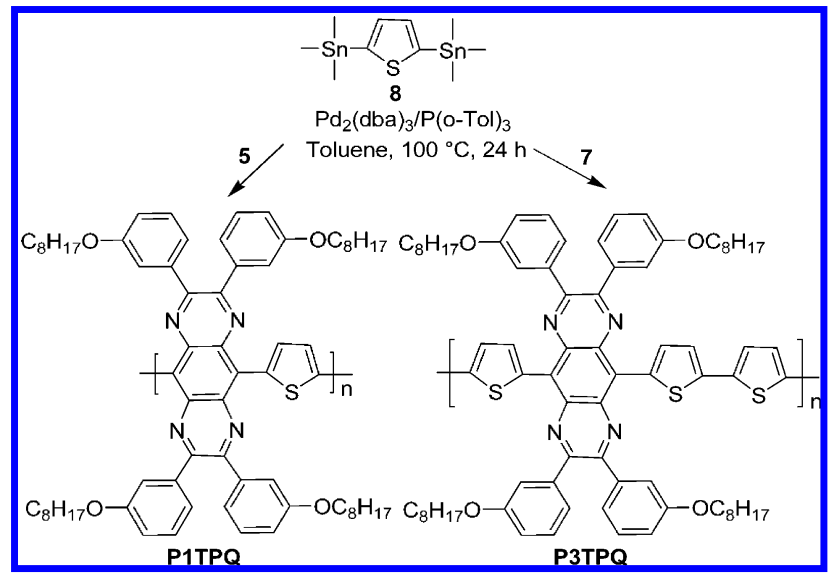

5 and 7 with 2,5-bis(trimethylstannyl)thiophene (8) via Stille coupling reaction with $\mathrm{Pd}_{2}(\mathrm{dba})_{3}$ and $\mathrm{P}(o-\mathrm{Tol})_{3}$ as catalyst resulted in the green polymers $\mathrm{P} 1 \mathrm{TPQ}$ and $\mathrm{P} 3 \mathrm{TPQ}$, respectively. Both polymers exhibited quite high molecular weights with $M_{\mathrm{n}}=75000$ and $M_{\mathrm{w}}=208000$ for P1TPQ and $M_{\mathrm{n}}=$ 100000 and $M_{\mathrm{w}}=537000$ for P3TPQ. High molecular weights proved to be favorable to achieve better morphology and higher PCE of the resulting polymer solar cells. ${ }^{8}$

The absorption spectra of the two polymers in chloroform solution and in film are plotted in Figure 1. The optical

(7) Coon, C. L.; Blucher, W. G.; Hill, M. E. J. Org. Chem. 1973, 38, 4243 .

(8) (a) Schilinsky, P.; Asawapirom, U.; Scherf, U.; Biele, M.; Brabec, C. J. Chem. Mater. 2005, 17, 2175. (b) Bijleveld, J. C.; Zoombelt, A. P.; Mathijssen, S. G. J.; Wienk, M. M.; Turbiez, M.; de Leeuw, D. M.; Janssen, R. A. J. J. Am. Chem. Soc. 2009, 131, 16616. 


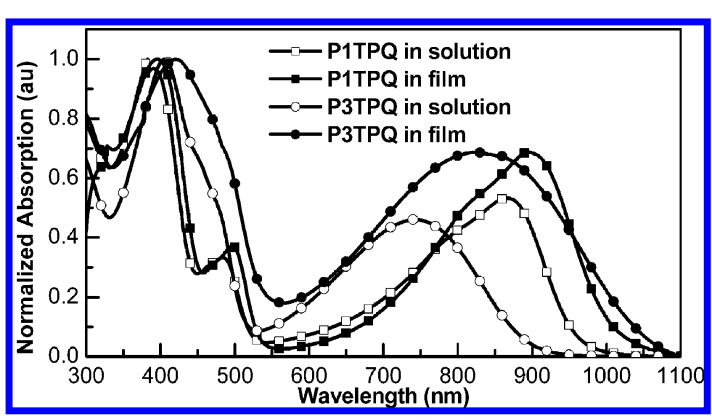

Figure 1. Absorption spectra of P1TPQ and P3TPQ in chloroform solution and in film.

bandgaps $\left(E_{\mathrm{g}}\right)$, defined by the onset of the absorption spectra of the films, are $1.2 \mathrm{eV}$ for P1TPQ and $1.1 \mathrm{eV}$ for P3TPQ, which demonstrate the two polymers to be rather small band gap polymers. Unlike the absorption maximum $\left(\lambda_{\max }\right)$ of a similar polymer PTBEHBQ reported by Zoombelt et al. that showed a small blue shift when going from solution to the solid state, ${ }^{9}$ the $\lambda_{\max }$ at long wavelength of P3TPQ showed a quite large red shift of ca. $90 \mathrm{~nm}$ and an increase in intensity. This phenomenon indicates good intermolecular ordering ( $\pi$-stacking/aggregates) in the solid state, which should benefit charge transport, and then higher performance can be expected in the resulting polymer solar cells.

To investigate if the HOMO and LUMO levels of the polymers match well with the acceptors [60]PCBM or [70]PCBM, the electrochemical behaviors of all the materials were measured under the same conditions by square wave voltammetry (SWV). ${ }^{10}$ The HOMO and LUMO levels determined from oxidation and reduction peaks are -5.73 and $-3.96 \mathrm{eV}$, respectively, for P1TPQ. The corresponding values for P3TPQ are -5.64 and $-3.90 \mathrm{eV}$, respectively. As shown in Figure S13 (Supporting Information), the reduction potentials of the two polymers are quite close to that of [60]PCBM, with an offset of $0.1-0.2 \mathrm{~V}$, which indicates that the electron transfer between polymers and [60]PCBM may not be so effective since it is generally considered that a minimum offset of $\sim 0.3-0.4 \mathrm{eV}$ between LUMO levels of electron donor and acceptor is necessary for efficient electron transfer. ${ }^{11}$

Bulk heterojunction solar cells were fabricated from P1TPQ and P3TPQ with a device architecture of glass/ITO/ PEDOT:PSS/active layer/LiF/Al. As summarized in Table 1 , the device results from the blends of polymers/[60]PCBM (optimized ratio is 1:3 for both polymers) in chloroform solution are not great with maximum PCE of $0.3 \%$ for P1TPQ and $0.9 \%$ for P3TPQ. The low short-circuit current density $\left(J_{\text {sc }}\right)$ can be partially attributed to the insufficient driving force for charge separation mentioned above.

(9) Zoombelt, A. P.; Fonrodona, M.; Turbiez, M. G. R.; Wienk, M. M.; Janssen, R. A. J. J. Mater. Chem. 2009, 19, 5336.

(10) Hellström, S.; Zhang, F. L.; Inganäs, O.; Andersson, M. R. Dalton Trans. 2009, 10032.

(11) (a) Scharber, M. C.; Wühlbacher, D.; Koppe, M.; Denk, P.; Waldauf, C.; Heeger, A. J.; Brabec, C. J. Adv. Mater. 2006, 18, 789. (b) Koster, L. J. A.; Mihailetchi, V. D.; Blom, P. W. M. Appl. Phvs. Lett. 2006, $88,093511$.
Table 1. Photovoltaic Parameters of the Devices

\begin{tabular}{ccccc}
\hline weight ratio & $J_{\mathrm{sc}}\left(\mathrm{mA} \mathrm{cm}^{-2}\right)$ & $V_{\mathrm{oc}}(\mathrm{V})$ & $\mathrm{FF}$ & $\mathrm{PCE}(\%)$ \\
\hline $\mathrm{P} 1 \mathrm{TPQ} /[60] \mathrm{PCBM}=1: 3$ & 0.8 & 0.71 & 0.58 & 0.3 \\
$\mathrm{P} 3 \mathrm{TPQ} /[60] \mathrm{PCBM}=1: 3$ & 3.5 & 0.51 & 0.51 & 0.9 \\
$\mathrm{P} 1 \mathrm{TPQ} /[70] \mathrm{PCBM}=1: 3$ & 1.5 & 0.66 & 0.50 & 0.5 \\
$\mathrm{P} 3 \mathrm{TPQ} /[70] \mathrm{PCBM}=1: 1$ & 2.5 & 0.51 & 0.34 & 0.4 \\
$\mathrm{P} 3 \mathrm{TPQ} /[70] \mathrm{PCBM}=1: 2$ & 8.7 & 0.50 & 0.40 & 1.7 \\
$\mathrm{P} 3 \mathrm{TPQ} /[70] \mathrm{PCBM}=1: 3$ & 7.3 & 0.52 & 0.54 & 2.1 \\
P3TPQ/[70]PCBM $=1: 4$ & 4.5 & 0.51 & 0.58 & 1.3 \\
\hline
\end{tabular}

[70]PCBM has similar electronic properties to [60]PCBM but a considerably higher absorption coefficient in the visible region because of its asymmetric chemical structure. ${ }^{12}$ Photovoltaic devices were made by using [70]PCBM as an acceptor instead of [60]PCBM. Although the performance improvement for P1TPQ was not obvious when [70]PCBM was used, the PCEs of the solar cells fabricated from blends of P3TPQ/[70]PCBM in $o$-dichlorobenzene (ODCB) solution displayed a significant increase. The weight ratios of P3TPQ and [70]PCBM were optimized from 1:1, 1:2, 1:3, to 1:4, and the related performance parameters are summarized in Table 1. A maximum PCE of $2.1 \%$ with an open-circuit voltage $\left(V_{\mathrm{oc}}\right)$ of $0.52 \mathrm{~V}$, a $J_{\mathrm{sc}}$ of $7.3 \mathrm{~mA} \mathrm{~cm} \mathrm{~cm}^{-2}$, and a fill factor $(\mathrm{FF})$ of 0.54 was obtained from the solar cells of $\mathrm{P} 3 \mathrm{TPQ} /[70] \mathrm{PCBM}=1: 3$ under illumination from an $\mathrm{AM}$ $1.5 \mathrm{G}$ solar simulator $\left(100 \mathrm{~mW} \mathrm{~cm}{ }^{-2}\right)$. Low $V_{\mathrm{oc}}$ is one of drawbacks for small band gap polymers. It is worth noting that the $V_{\text {oc }}$ of $0.52 \mathrm{~V}$ is rather high for a polymer with a band gap as small as $1.1 \mathrm{eV}$. The $V_{\text {oc }}$ has achieved the upper limit of its theoretical value according to the empirical formula $e V_{\mathrm{oc}}=E_{\mathrm{g}}-0.6 \mathrm{eV} \cdot{ }^{13}$ Compared to the $J_{\mathrm{sc}}(3.5 \mathrm{~mA}$ $\mathrm{cm}^{-2}$ ) from the device of P3TPQ/[60]PCBM, the dramatically increased $J_{\mathrm{sc}}\left(7.3 \mathrm{~mA} \mathrm{~cm}{ }^{-2}\right)$ from the device of P3TPQ/ [70]PCBM indicates that the charge transfer between P3TPQ and [70]PCBM is effective, which means the offset (0.22 $\mathrm{eV}$ ) between the LUMO levels of P3TPQ and [70]PCBM should be sufficient for electron transfer.

The current density-voltage $(J-V)$ curves of the solar cells from P3TPQ/[70]PCBM $=1: 3$ both in the dark and under illumination are shown in Figure 2a. The dark $J-V$ curve shows a typical diode characteristic with very small leakage current at $-1 \mathrm{~V}$. To confirm the accuracy of the measurement of the devices, the corresponding external quantum efficiency (EQE) of the solar cell was measured under illumination of monochromatic light. The $J_{\text {sc }}$ calculated from integration of the EQE with an AM 1.5G reference spectrum agrees well with the $J_{\text {sc }}$ obtained from the $J-V$ measurement. As shown in Figure 2b, the photoresponse of the solar cell from P3TPQ/[70]PCBM = 1:3 in the visible region was significantly enhanced when going from [60]PCBM to [70]PCBM. This is consistent with the aborption spectra

(12) Wienk, M. M.; Kroon, J. M.; Verhees, W. J. H.; Knol, J.; Hummelen, J. C.; van Hal, P. A.; Janssen, R. A. J. Angew. Chem. Int. Ed. 2003, 42, 3371.

(13) Veldman, D.; Meskers, S. C. J.; Janssen, R. A. J. Adv. Funct. Mater. 2009, 19, 1939. 


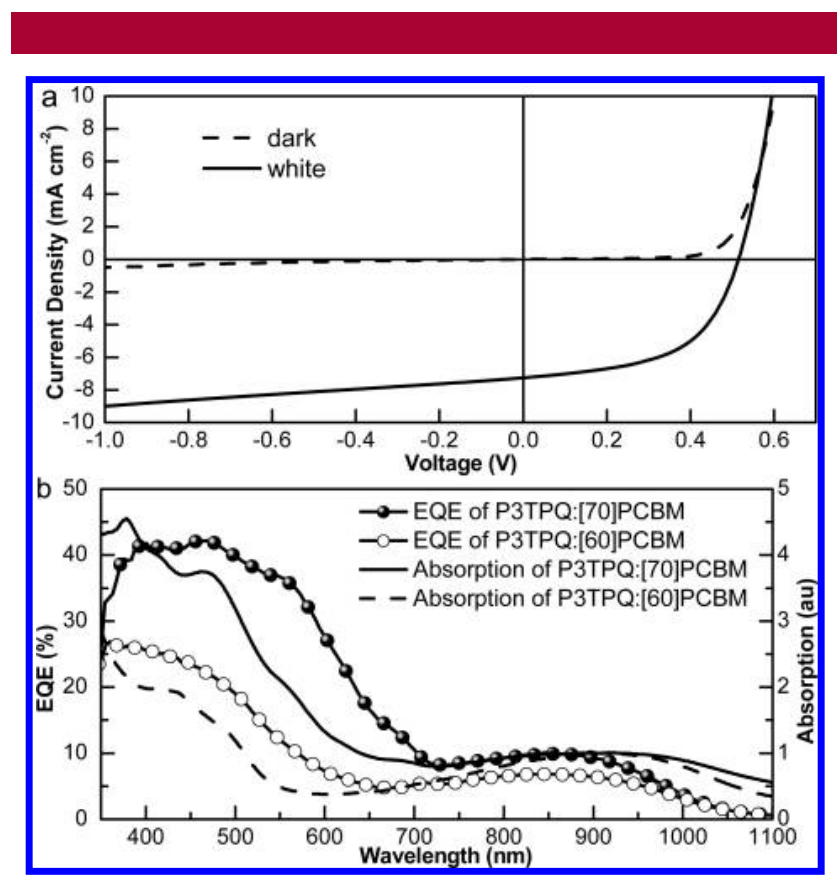

Figure 2. (a) $J-V$ characteristics of $\mathrm{P} 3 \mathrm{TPQ} /[70] \mathrm{PCBM}=1: 3$ based solar cells under an AM 1.5G illumination $\left(100 \mathrm{~mW} \mathrm{~cm}^{-2}\right)$ and in the dark. (b) EQE profiles from the devices of P3TPQ/[70]PCBM $=1: 3$ and $\mathrm{P} 3 \mathrm{TPQ} /[60] \mathrm{PCBM}=1: 3$ as well as the absorption spectra of the films from $\mathrm{P} 3 \mathrm{TPQ} /[70] \mathrm{PCBM}=1: 3$ and $\mathrm{P} 3 \mathrm{TPQ} /$ $[60] \mathrm{PCBM}=1: 3$ (normalized at $900 \mathrm{~nm}$ for comparison).

of the films from the blends of $\mathrm{P} 3 \mathrm{TPQ} /[60] \mathrm{PCBM}=1: 3$ and $\mathrm{P} 3 \mathrm{TPQ} /[70] \mathrm{PCBM}=1: 3$ measured under similar conditions. This is the main reason for the improvement of the PCE when [70]PCBM was used as the acceptor instead of [60]PCBM in the solar cells. The photoresponse at long wavelength region originates from P3TPQ with a peak at $860 \mathrm{~nm}$ and an edge at $1.1 \mu \mathrm{m}$. To our knowledge, this is one of the highest PCEs for small band gap polymers with a band gap as small as $1.1 \mathrm{eV}$ and a photoresponse up to $1.1 \mu \mathrm{m}$ reported to date. ${ }^{4 \mathrm{c}, \mathrm{d}, 14}$

The morphology of the active layer is very important for BHJ polymer solar cells and can influence charge separation and transport. ${ }^{15}$ To gain insight into the morphology of the

(14) (a) Wen, L.; Duck, B. C.; Dastoor, P. C.; Rasmussen, S. C. Macromolecules 2008, 41, 4576. (b) Zhou, E.; Wei, Q.; Yamakawa, S.; Zhang, Y.; Tajima, K.; Yang, C.; Hashimoto, K. Macromolecules 2010, 43,821 .

(15) Hoppe, H.; Sariciftci, N. S. J. Mater. Chem. 2006, 16, 45. active layer, atomic force microscopy (AFM) was used. As shown in Figure 3, the blend from P3TPQ/[70]PCBM $=1: 3$

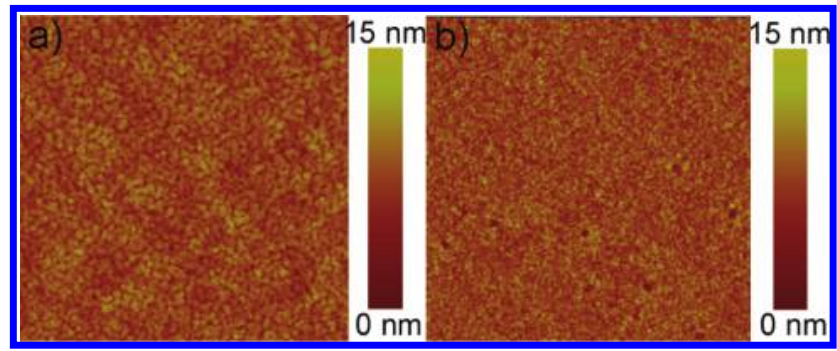

Figure 3. AFM height images $(5 \mu \mathrm{m} \times 5 \mu \mathrm{m})$ of the films spincoated from (a) P3TPQ/[60]PCBM $=1: 3$ in chloroform solution and (b) P3TPQ/[70]PCBM = 1:3 in ODCB solution.

in ODCB solution has a smaller domain size compared to the blend from $\mathrm{P} 3 \mathrm{TPQ} /[60] \mathrm{PCBM}=1: 3$ in chloroform solution, which indicates that there is a more optimal morphology in $\mathrm{P} 3 \mathrm{TPQ} /[70] \mathrm{PCBM}=1: 3$ film. This is an important reason for the improved performance of the devices based on P3TPQ/[70]PCBM $=1: 3$.

In conclusion, the preparation of $\mathbf{2}$, which is the key compound for achieving strong acceptors, was modified by using the mixture of fuming $\mathrm{HNO}_{3}$ and fuming $\mathrm{CF}_{3} \mathrm{SO}_{3} \mathrm{H}$ as the nitrating agent. The great improvement in yield (from 30 to $85 \%$ ) makes the important imtermediate compound 2 readily available. Accordingly, two new small band gap polymers P1TPQ and P3TPQ were synthesized with high molecular weights. P3TPQ showed interesting photovoltaic properties with $V_{\mathrm{oc}}$ of $0.52 \mathrm{~V}$, PCE over $2 \%$, and a photoresponse up to $1.1 \mu \mathrm{m}$ in BHJ polymer solar cells. This work will be of importance in guiding the design and development of very small band gap polymers for polymer solar cells and NIR detectors.

Acknowledgment. This work was financed by the Swedish Energy Agency through projects Polarge. We thank the Knut and Alice Wallenberg Stiftelse for instrument grants.

Supporting Information Available: Experimental procedures, electrochemical measurement, and device fabrication. This material is available free of charge via the Internet at http://pubs.acs.org.

OL1020724 